\title{
1. Untangling the climate-food web: achieving food security and agricultural climate-resilience Mary Jane Angelo
}

\section{INTRODUCTION}

Any lingering doubts that climate change, if unchecked, will cause significant global harm were put to rest at the United Nations Climate Change Conference (Conference of the Parties (COP21)) in Paris in late 2015. For the first time, it appears that the international community has taken seriously the threat of climate change and the urgency to act. In what has been hailed as 'an extraordinary effort at international diplomacy', 195 nation states rallied around the call to ensure that the globe does not warm by more than 2 degrees $\mathrm{C}$ to avoid the catastrophic impacts that would likely occur with any greater increase in temperature.

Many believe that the agreement that grew out of COP21, referred to as the 'Paris Agreement', represents the last best hope for avoiding catastrophic impacts from climate change. In the agricultural arena, a failure to fulfill the commitments made in the Paris Agreement could result in dramatic increases in hunger and poverty throughout the world. Even if the promises of the Paris agreement are realized and countries throughout the world succeed in substantially reducing GHG emissions, climate change impacts will occur. Without substantial GHG emission reductions to slow the pace of change, these impacts could be severe and could dramatically threaten food security.

Although the impacts of climate change on agriculture will vary based on geologic location and other factors, there is widespread agreement that climate change will likely result in significantly decreased crop yields, increased food prices, and decreased food security for millions of people, particularly in the developing world. In its 2014 report, the IPCC concluded, that while projected impacts vary across crops and regions,

Coral Davenport, 'Nations Approve Landmark Climate Accord in Paris' The New York Times (Le Bourget, France, 12 Dec 2015), accessed 10 October 2016 at http://www.nytimes.com/2015/12/13/world/europe/climate-change-accordparis.html?smprod=nytcore-ipad\&smid=nytcore-ipad-share\&_r=. 


\section{Research handbook on climate change and agricultural law}

crop yields could decrease by more than 25 percent. ${ }^{2}$ These changes will take place during the same timeframe that a larger and generally wealthier population will raise the demand for agricultural production by approximately 60 percent.

Never in history has there been an anthropogenic environmental problem as dramatic as the climate change crisis. ${ }^{3}$ As an ever-increasing body of scientific research continues to demonstrate the link between anthropogenic carbon emissions and the continued increases in global atmospheric temperatures, the vast majority of the world's scientists concur that climate change is already occurring and will continue to occur far into the future. ${ }^{4}$ Scientists project that, in the absence of substantial reductions in global GHG emissions, the expected increase in global temperature will produce significant climatic changes that will lead to a multitude of environmental harms, including continued warming, ${ }^{5}$ sea level rise, ${ }^{6}$ salt water intrusion, increased precipitation and flooding in some areas, ${ }^{7}$ increased incidence of drought in many geographic locales, ${ }^{8}$ increased frequency of heat waves, ${ }^{9}$

\footnotetext{
2 See IPCC 'Climate Change 2014: Synthesis Report Summary for Policy Makers' (2014).

3 See Raymond B Ludwiszewski and Charles H Haake, Climate Change: A
} Heat Wave of New Federal Regulation and Legislation, FED. LAW, June 2009, at 32 (explaining that global climate change is currently the top environmental concern). See also see IPCC 'Climate Change 2014: Synthesis Report Summary for Policy Makers' (2014).

4 Intergovernmental Panel on Climate Change, 'Climate Change 2013: The Physical Science Basis, Summary For Policymakers' (2013) 17 (stating that 'It is extremely likely that more than half of the observed increase in global average surface temperature from 1951 to 2010 was caused by the anthropogenic increase in greenhouse gas concentrations and other anthropogenic forces together'), ('IPCC Report'), accessed 10 October 2016 at http://ipcc.ch/pdf/assessment-report/ ar5/wg1/WG1AR5_SPM_FINAL.pdf; Endangerment and Cause or Contribute Findings for Greenhouse Gases Under Section 202(a) of the Clean Air Act; Final Rule, 74 Fed. Reg. 66496-66546 (15 December 2009).

5 IPCC Report, above note 4 at 7 states that it is 'virtually certain' ( $>99 \%$ probability of occurrence) that future warming will occur. For an explanation of the probability terminology used in the IPCC report, see IPCC 'Climate Change 2014: Synthesis Report Summary for Policy Makers' (2014) at 2.

6 IPCC Report, above note 4 at 7, It is 'very likely' $(99-100 \%$ probability of occurrence) that there will be increased incidents of high sea level.

7 It is 'likely over many areas' (66-100\% probability of occurrence) that there will be increased heavy precipitation in some areas of the globe. Id.

8 It is 'likely' (66-100\% probability of occurrence) that there will be an increased number of droughts. $I d$.

9 It is 'very likely' (99-100\% probability of occurrence) that there will be an increased number of heat waves. Id. 
and more intense severe weather events. ${ }^{10}$ These impacts will have significant consequences for agriculture and food security. Achieving the goal of global food security in the face of these anticipated dramatic impacts will require innovative and transformative approaches that go well beyond the COP21 commitments to reduce GHG emissions, to create a more climate-resilient agricultural system.

This volume, which focuses on agriculture and climate change, is part of a broader series on climate change. The theme of this volume centers on the goal of achieving a low-carbon climate resilient agricultural system that provides for future food security throughout the developed and developing regions of the globe. We invited top legal, science and social science scholars from around the world to contribute chapters to explore issues related to the types of domestic and international agricultural and environmental laws and policies that address climate change mitigation and adaptation and the challenges of attempting to reconcile these laws and policies with agricultural development, economic growth, food security objectives and sustainable livelihoods. This volume is intentionally interdisciplinary and international in scope and includes contributions representing a range of geographic perspectives, representing both the northern and southern hemispheres.

The contributions to this volume seek to address following issues:

(1) To what extent do domestic agricultural laws and policies in the northern and southern hemispheres address climate mitigation and adaptation?

(2) Are the policies and legal tools in existing national agricultural law frameworks sufficient for human and agro-ecosystem adaptation?

(3) What are the legally relevant challenges to marrying climate mitigation and adaptation with agricultural development, economic growth, food security objectives and sustainable livelihoods?

(4) How do individual country's agricultural law and policy provisions for mitigation and adaptation 'measure up' against the expectations of international and/or regional climate law and policy?

(5) What are the weaknesses, strengths, gaps and innovations in existing agricultural laws and policies?

(6) What new and innovative tools can be employed to address climate change mitigation and adaptation in the agricultural sector?

(7) What are the remaining research needs?

10 It is 'more likely than not' ( $50-100 \%$ probability of occurrence) that there will be more intense tropical cyclone events. $I d$. 
Following this introductory chapter, Chapter 2 provides Jonathan Verschuuren's broad overview of international law on climate change as it relates to agriculture. In Chapter 3 Lance Gunderson provides a scientific perspective on the complex and dynamic nature of agroecosystems in a broader 'systems' ecology framework. In Chapter 4 Paul Martin then takes the general concept of 'systems thinking' and proposes extending it as a model for climate change governance. The next several chapters address a variety of legal tools for climate change adaptation and mitigation in the context of agriculture: water law (Chapter 5, Robert Adler); invasive species law (Chapter 6, Elodie Le Gal); genetically modified organism law (Chapter 7, Rebecca Bratspies); land use law (Chapter 8, Keith Hirokawa); and intensive animal farming law (Chapter 9, Michelle Nowlin and Emily Spiegel). The volume then turns to a series of chapters related to the roles of trade, finance, markets and government subsidies, including chapters addressing: international trade law (Chapter 10, Christian Häberli); payments for ecosystem services (Chapter 11, JB Ruhl); and government subsidies of biofuels (Chapter 12, Sérgio Sauer, José Paulo Pietrafesa and Pedro Araujo Pietrafesa). Finally in the last chapters the volume explores issues related to legal protection of agricultural community interests in the context of climate change adaptation, including chapters on: adaptation in smallholder agriculture (Chapter 13, Robert Kibugi); agriculture and land use conflicts (Chapter 14, Amanda Kennedy and Amy Cosby); and climate change and land grabbing (Chapter 15, Akachi Odoemene).

\section{THE CLIMATE CHANGE-FOOD SECURITY LINK}

There is no longer any doubt that human actions have set into motion a transformation of the Earth's climate in a way that humans have never done before. Although the imperative to mitigate the ongoing emissions of greenhouse gases that are at the root of this change continues, there is no longer any doubt that human societies throughout the world will be affected and will have to find ways to adapt to the changes. The anticipated changes are numerous and include temperature increase, carbon dioxide increase, increased frequency and extent of extreme weather conditions, increased drought in many areas and increased severe storm events and flooding in others, increased movement of pest and disease populations, increased pest and disease outbreaks, saltwater intrusion along the coasts and loss of land due to sea level rise loss. The aggregate effects of these changes are predicted to have severe impacts on food security due to significant decreases of agricultural production in many areas, significant food price increases, decreased nutritional value of some foods and an 
increased risk of health problems due to adulterated and unsafe foods. All of these changes will be occurring against a backdrop of a growing global population and increased food consumption and demands for different food in regions with significant economic growth. Although all aspects of society will be impacted to some extent, perhaps the greatest challenge of these changes will be feeding the growing global population.

The United Nations Food and Agriculture Organization (FAO) defines 'food security' as existing when 'all people at all times have physical or economic access to sufficient safe and nutritious food to meet their dietary needs and food preferences for an active and healthy life'. ${ }^{11}$ According to the FAO the four dimensions of food security are: food availability, food accessibility, food utilization and food systems stability. The adverse impacts of climate change, such as increased crop loss from pests, disease or drought, that decrease food production will reduce food availability. Increased food prices and reduced farm incomes will reduce food accessibility. Climate impacts that affect the safety and nutritional value of food will reduce food utilization. Finally climate changes that disrupt food systems due to extreme climate events will reduce food system stability.

Currently the global population exceeds 7 billion people ${ }^{12}$ and that number is expected to increase by one-third by $2050 .{ }^{13}$ The majority of population growth will occur in developing countries. Population growth coupled with growing income and consumption will result in a need for global food production to increase by 60 percent by 2050 . To avoid a food security catastrophe we must find ways to transform our agricultural systems by both finding ways to reduce the substantial contributions of GHG emissions from agriculture to help to mitigate climate change impacts and by finding ways to adapt agricultural systems to the inevitable changes that are, and will continue, to occur regardless of the success of mitigation efforts. Achieving these mitigation and adaptation goals will require, among other things, preserving natural resources and vital ecosystem services, while at the same time transitioning to more productive agricultural production systems that have greater climate resiliency that will enable them to adapt to greater perturbations and long-term climate

11 United Nations Food and Agriculture Organization, Climate Change and Food Security: A Framework Document (2008) 3, accessed 10 October 2016 at http://www.fao.org/forestry/15538-079b31d45081fe9c3dbc6ff34de4807e4.pdf.

${ }_{12}$ Sam Roberts, 'U.N. Says 7 Billion Now Share the World' The New York Times (31 October 2011), accessed 10 October 2016 at http://www.nytimes. com/2011/11/01/world/united-nations-reports-7-billion-humans-but-others-dontcount-on-it.html?_r=1.

13 United Nations Food and Agriculture Organization, above note 11 at 42. 
variability. Creating a more resilient agricultural system will require a major transformation in the way land, water, soil nutrients and genetic resources are managed, which in turn will require changes in national, local and international laws and policies as well as changes in financial mechanisms.

Climate change and agriculture are closely linked, as each can have dramatic impacts on the other. ${ }^{14}$ Industrialized agriculture relies heavily on fossil fuel-intensive farming, processing and distribution systems, which emit greenhouse gases. ${ }^{15}$ Throughout the developed world a significant portion of all fossil fuel use is for agricultural activities such as pesticide and fertilizer production and application, mechanized plowing and harvesting, mechanized processing and distribution of farm products via fossil fuel powered transportation systems. ${ }^{16}$ The predicted impacts to agriculture due to increase in temperature, altered rainfall patterns and increased extreme weather events are expected to result in substantial reductions in global agricultural production and significant increases in food prices. Reduced food production and higher food prices will further compromise food security concerns in regions of the world which are already food insecure and may cause increased food security problems in other regions.

\subsection{Agriculture's Contribution to Climate Change}

Agricultural systems are significant contributors to climate change both in terms of GHG emissions and because of conversion of forestland, which can serve as a carbon sink, into cropland. Most of the developed world relies on fossil fuel-heavy industrialized agricultural practices to produce high yields. Chemical pesticides and fertilizers used in industrialized farming are derived from fossils fuels ${ }^{17}$ and heavy equipment used

14 Mary Jane Angelo, 'Corn, Carbon and Conservation: Rethinking US Agricultural Policy in a Changing Global Environment' (2010) 17 Geo. Mason L. Rev. 593.

15 William S Eubanks II, 'A Rotten System: Subsidizing Environmental Degradation and Poor Public Health with Our Nation's Tax Dollars' (2009) 28 Stan. Envtl. L.J. 213, 269-70; Angelo, above note 14.

${ }_{16}$ See Id.; Peter Warshall, 'Tilth and Technology: The Industrial Redesign of Our Nation's Soils' in Andrew Kimbrell (ed.), Fatal Harvest: The Tragedy of Industrial Agriculture 221, 225 (Foundation for Deep Ecology/Island Press 2002). Jason J Czarnezki and Elisa K Prescott, 'Environmental and Climate Impacts of Food Production, Processing, Packaging, and Distribution' in Mary Jane Angelo, Jason J Czarnezki and William S Eubanks, II (eds), Food, Agriculture and Environmental Law (Environmental Law Institute 2013).

17 Warshall, above note 16 at 221, 225. 
for growing, harvesting, transportation and processing use significant amounts of gasoline and diesel fuel. ${ }^{18}$ The food sector accounts for approximately 30 percent of the world's total energy consumption and over 20 percent of greenhouse gas emissions. ${ }^{19}$

A particular industrial agricultural practice, concentrated animal feeding operations, is responsible for the release of significant amounts of methane gas, a natural animal waste and one of the most powerful GHGs. ${ }^{20}$ In these operations substantial amounts of methane gas are emitted by hundreds or thousands of animals confined to a small areas and fed large quantities of corn and other grains. ${ }^{21}$ Methane gas is over 20 times more powerful than carbon dioxide in exerting a greenhouse effect. ${ }^{22}$ It is estimated that GHG emissions from livestock account for almost two-thirds of all GHG emissions. Of those two-thirds, 78 percent is in the form of methane. According to FAO estimates, with the right policies and technologies, it is possible to reduce GHG emissions from livestock by about 30 percent. ${ }^{23}$

On another front, in our search for alternative renewable fuels, we may have unwittingly accelerated agriculture's contribution to climate change by substantially increasing corn ethanol production. ${ }^{24}$ Between the $1980 \mathrm{~s}$ and 2007 corn ethanol production in the US increased from approximately

18 Czarnezki and Prescott, above note 16; William S. Eubanks II, 'The Sustainable Farm Bill: A Proposal for Permanent Environmental Change' (June 2009) 39 ELR 10493, 10504; Warshall, above note 16, at 225.

19 Food and Agriculture Organization of the United Nations, 'Energy-Smart Food for People and Climate' (2011) 49, accessed 10 October 2016 at http://www. fao.org/docrep/014/i2454e/i2454e00.pdf.

20 See generally Hannah MM Connor, 'The Industrialization of Animal Agriculture: Connecting a Model With Its Impacts on the Environment' in Angelo, Czarnezki and Eubanks, Food, Agriculture and Environmental Law (2013).

${ }_{21}$ H Steinfeld et al, Food and Agriculture Organization of the United Nations, 'Livestock's Long Shadow' (2006) 271.

22 Ibid at xxi.

23 Gerber, P.J., et al., Food and Agriculture Organization of the United Nations, 'Tackling Climate Change Through Livestock: A Global Assessment of Emissions and Mitigation Opportunities' (2013) xiii, accessed 10 October 2016 at http://www.fao.org/3/i3437e.pdf.

${ }_{24}$ High Level Panel of Experts on Food Security and Nutrition, 'Biofuels and Food Security: A report by the High Level Panel of Experts on Food Security and Nutrition of the Committee on World Food Security' (2013) 50, accessed 10 October 2016 at http://www.fao.org/fileadmin/user_upload/hlpe/hlpe_documents/ HLPE_Reports/HLPE-Report-5_Biofuels_and_food_security.pdf; Timothy D Searchinger et al., 'Use of U.S. Croplands for Biofuels Increases Greenhouse Gases through Emissions from Land Use Change' (2008) 319 Science 5867, $1238-40$. 
175 million gallons to almost 6.5 billion gallons..$^{25}$ By 2011, 40 percent of all corn grown in the US went to ethanol production, up from less than 1 percent in $1980 .{ }^{26}$ Although corn ethanol is considered to be a 'renewable' source of energy, ${ }^{27}$ there is widespread doubt that its use will reduce GHG emissions in any meaningful way. ${ }^{28}$ In the US, a long running series of federal subsidy programs have incentivized corn ethanol production. ${ }^{29}$ In recent years, a renewable fuel standard mandated by the Energy Policy Act of 2005 and the Energy Independence and Security Act of 2007 created a strong market for corn ethanol. ${ }^{30}$ These policies promote increased industrialized corn production via large-scale monoculture production. Similar incentives for biofuel production exist in other parts of the world. In Chapter 12, Sérgio Sauer, José Paulo Pietrafesa and Pedro Araujo Pietrafesa describe legal incentives and financial investments that have increased demand for sugarcane as an alternative energy source to replace petroleum. The authors describe GHG emissions from sugarcane biofuel production and use, and describe how this energy source results in loss

25 James A Duffield, Irene M Xiarchos and Steve A Halbrook, 'Ethanol Policy: Past, Present, and Future' (2008) 53 S.D. L. Rev. 425, 425; Karl R Rabago, 'A Review of Barriers to Biofuel Market Development in the United States' (2008) 2 Envtl. \& Energy L. \& Pol'y J. 211, 212 (describing the remaining barriers to full commercial success for biofuels in the United States).

26 'Percentage of Corn Crop Used for Ethanol' accessed 13 November 2016 at http://www.ers.usda.gov/topics/crops/corn/policy/.

27 'Growth Energy, About Growth Energy', accessed 10 October 2016 at http://www.growthenergy.org/about-growth-energy/.

28 Christopher Jensen, 'Caution Flags Raised Over Ethanol Industry's 15 percent Solution' The New York Times (10 May 2009).

${ }_{29}$ Wallace E Tyner, 'The US Ethanol and Biofuels Boom: Its Origins, Current Status, and Future Prospects' (2008) 58 Bioscience 646, 646; Robert W Hahn, 'Ethanol: Law, Economics, and Politics' (2008) 19 Stan. L. \& Pol'y Rev. 434, 437-45 (describing how federal subsidies have driven the development of the ethanol fuel industry in the United States); Gary D. Libecap, 'Agricultural Programs with Dubious Environmental Benefits: The Political Economy of Ethanol' in Rodger E Meiners and Bruce Yandle (eds), Agricultural Policy and the Environment (Rowan \& Littlefield Publishers 2003) (quoting David Pimentel) 89.

30 Energy Policy Act of 2005, Pub. L. No. 109-58, 119 Stat. 594; Energy Independence and Security Act of 2007, Pub. L. No. 110-140, 121 Stat. 1492; Mark Holt and Carol Glover, 'Cong. Research Serv., Energy Policy Act of 2005: Summary and Analysis of Enacted Provisions 100' (2006), accessed 10 October 2016 at http://www.congressionalresearch.com/RL33302/document.php?study= Energy+Policy+Act+of+2005+Summary+and+Analysis+of+Enacted+Provisi ons; Fred Sissine, 'Cong. Research Serv., Energy Independence and Security Act of 2007: A Summary of Major Provisions 6' (2007), accessed 10 October 2016 at http://www1.eere.energy.gov/manufacturing/tech_assistance/pdfs/crs_report_ energy_act_2007.pdf. 
of biodiversity and deforestation in Brazil. Similarly Akachi Odoemene, in Chapter 15, describes how the push for biofuel production is a major contributor to the 'land grabbing' phenomenon that is occurring in Africa and other parts of the world.

The increased conversion of forestland to agriculture, particularly in the context of land grabbing in parts of the developing world, is another major contributor to climate change. As forested land is burned or otherwise cleared to make way for crops and pasture, carbon preciously contained in forest biomass and organic soils is released into the atmosphere. Although crop plants may absorb carbon, the carbon is typically held in the crop biomass for short periods of time. The land grabbing phenomenon described in Chapter 15 has become a significant driver of land conversion. As Odoemene explains, the 2007-2008 global food crisis brought on by a combination of extreme weather conditions and the global financial crisis, led to a dramatic rise in food prices sparking fears of food insecurity. These fears led countries with net food import balances to look for ways to achieve food security and independence, often by investing in large areas of land in developing countries. For example as China experienced rapid economic growth and its more affluent population demanded more and different foods, it became a net food importer. To guarantee food security and independence the Chinese government, along with private investors, began to purchase enormous areas of arable land in other countries, contributing to deforestation and thus increasing atmospheric carbon.

\subsection{Climate Change Impacts on Agriculture}

Not only is agriculture a significant contributor to global climate change, but it is also a segment of the economy that will experience some of the most serious impacts of climate change. The IPCC predicts that the most significant impacts of climate change will be to agriculture, particularly in the developing world. ${ }^{31}$ The adverse effects of climate change on agriculture will vary greatly depending on geographic location and regional variation in agricultural systems..$^{32}$ The most dire concern over the effect of climate change on agriculture is regarding how it will alter crop yield, which is directly linked to food prices and food security. The anticipated impact on crop yield will result from a number of likely changes including

31 Purnamita Dasgupta et al., 'Rural Areas' in Climate Change 2014: Impacts, Adaptation, and Vulnerability. (Fifth Assessment Report of the Intergovernmental Panel on Climate Change 2014) 631.

32 Susan Charles, 'Climate Change: Impacts On Food Safety' (2011) 26 Sum Nat. Resources \& Env’t 44. 
changes in precipitation, in temperature, in sea level rise, in carbon dioxide levels and in crop disease and pest outbreaks.

One of the most significant risks to agriculture will involve water resources. Altered rainfall patterns are expected to cause droughts in some regions and flooding in others. ${ }^{33}$ These alterations will likely worsen water shortages in many already water-stressed areas. ${ }^{34}$ Increased temperatures will further exacerbate water scarcity, which in turn will result in decreased crop yields. ${ }^{35}$ The most dramatic changes in precipitation and temperature are likely to occur in the poorest and most vulnerable regions in the developing world, ${ }^{36}$ which are expected to experience disproportionate risks to food security. In Chapter 5 of this volume Robert Adler explores the increasing need for water to grow food for an expanding population with rising affluence and changing food preferences. He explores the impacts of climate change on the relationship between water and agriculture and the degree to which domestic and international water law will need to change to adapt to those impacts.

As the effects of climate change become more prevalent and widespread, the potential to greatly impact global food security will be more apparent. ${ }^{37}$ Temperature increases, altered precipitation patterns and greater weather extremes will adversely affect global and regional food production, which will result in reduced food availability and food accessibility. The world's poorest and most vulnerable regions are likely to experience the most dramatic and harmful changes in precipitation and temperature, ${ }^{38}$ resulting in disproportionate food security impacts. Exacerbated food insecurity in the poorest regions of the world will present increased challenges as to the ongoing struggle to meet a growing global population's demand for food.

\footnotetext{
33 Ibid.

34 Ibid.

35 Ibid.

36 Ibid.

37 The United Nations Food and Agriculture Organization defines 'food security' as existing when 'all people at all times have physical or economic access to sufficient safe and nutritious food to meet their dietary needs and food preferences for an active and healthy life'. The FAO definition encompasses four dimensions: food availability, food accessibility, food utilization, and food systems stability. FAO CC \& Food Security, 3.

38 Charles, above note 32 at 44.
} 


\section{ACHIEVING FOOD SECURITY AND A CLIMATE RESILIENT AGRICULTURE THROUGH MITIGATION AND ADAPTATION}

As the globe warms while simultaneously global populations grow larger and more affluent, agriculture faces three major and interconnected challenges: (1) food security; (2) adaptation to climate change; and (3) climate change mitigation. ${ }^{39}$ To adequately address these challenges, radical changes to our food production systems will be necessary. To meet growing food needs in a sustainable manner, we will need to find ways to produce more food with more efficient use of natural resources. Food systems must become more resilient to both the gradual changes and extreme events caused by climate change.

Strategies for addressing climate change can generally be divided into two broad categories: mitigation strategies and adaptation strategies. Mitigation strategies are designed to avoid the unmanageable impacts of climate change by reducing GHG emissions. Agricultural mitigation strategies reduce $\mathrm{GHG}$ emissions and sequester carbon through less fossil fuel-dependent more sustainable agricultural practices. ${ }^{40}$ Adaptation strategies are designed to manage the unavoidable effects of climate change. In the context of agriculture and food security, these strategies seek to build agricultural systems that can adapt to maintain adequate food production under changing climatic conditions. ${ }^{41}$ Ideally sufficient mitigation strategies would be employed to avoid most impacts of climate change. To date most of the strategies that have been employed in the US and other developed countries have fallen under the category of mitigation. ${ }^{42}$ Given the modest success of these strategies, research predicts that even if the atmospheric concentrations of GHGs could be stabilized at current levels, impacts on agricultural production

39 Food and Agriculture Organization of the United Nations 2013, 'ClimateSmart Agriculture Source Book' (2013), accessed 10 October 2016 at http://www.fao. org/3/i3325e.pdf.

40 Ibid; United Nations Food and Agriculture Organization, 'Climate Change and Food Security: A Framework Document' (2008) ('FAO Food Security') xi, accessed 10 October 2016 at http://www.fao.org/forestry/15538-079b31d45081fe9 c3dbc6ff34de4807e4.pdf.

41 Ibid.

42 JB Ruhl, 'Climate Change Adaptation and the Structural Transformation of Environmental Law’ (2010) 40 Envtl. L. 363, 374-5; Robin Kundis Craig, 'Stationarity is Dead' - Long Live Transformation: Five Principles for Climate Change Adaptation Law' (2010) 34 Harv. Envtl. L. Rev. 9, 18-19. 


\section{Research handbook on climate change and agricultural law}

will continue well into the future. ${ }^{43}$ Thus it is critical that policy solutions include both mitigation and adaptation strategies to ensure that agricultural production, and consequently food security, is not threatened by climate change. ${ }^{44}$

\subsection{Mitigation Strategies}

The US Global Change Research Program defines mitigation as 'options for limiting climate change by, for example, reducing heat-trapping emissions such as carbon dioxide, methane, nitrous oxide, and halocarbons, or removing some of the heat trapping gases from the atmosphere'. ${ }^{45}$ Mitigation strategies seek to avoid the unmanageable consequences of climate change by reducing GHG emissions or finding ways to capture or sequester carbon to reduce atmospheric concentrations of GHGs. ${ }^{46}$ Effective mitigation measures to keep global temperature increases below 2 degrees $\mathrm{C}$ are critical to avoiding the most catastrophic impacts of climate change, including substantial reduction in global food security. ${ }^{47}$

As described above agriculture is a significant contributor to climate change and thus is a logical target for mitigation strategies. Nevertheless as Jonathan Verschuuren describes in Chapter 2, agriculture has played a minor role in the UNFCCC. Neither the Paris Agreement nor the Kyoto Protocol treat agriculture's contribution to climate change in more than a cursory manner. For example under Kyoto only 2.5 percent of registered projects included in the Clean Development Mechanism were related to agriculture. Verschuuren also describes the modest role that agriculture played in the Paris Agreement, but concludes that despite the limited

43 Steven K Rose and Bruce A McCarl, American Agricultural Economics Association, 'Greenhouse Gas Emissions, Stabilization and the Inevitability of Adaption: Challenges for US Agriculture' (2008) 23 Choices 15, accessed 10 October 2016 at www.choicesmagazine.org/2008-1/theme/05.pdf.

44 IPCC Report, above note 4 at 17-18.

45 US Global Change Research Program, Global Climate Change Impacts in the United States 10-11 (2009) ('USGCRP, Impact Report'), accessed 10 October 2016 at http://downloads.globalchange.gov/usimpacts/pdfs/climate-impacts-report. pdf.

46 BS Fisher et al., 'Issues Related to Mitigation in the Long Term Context' in B Metz, OR Davidson, PR Bosch, R Dave, LA Meyer (eds), Climate Change 2007: Mitigation. Contribution of Working Group III to the Fourth Assessment Report of the Inter-governmental Panel on Climate Change 171 (2007), accessed 10 October 2016 at http://www.ipcc.ch/pdf/assessment-report/ar4/wg3/ar4-wg3-chapter3.pdf; FAO Food Security above note 40 at 8; Craig, above note 42, at 19.

47 FAO Food Security, above note 40 at 59. 
attention paid to agriculture, ultimately the Paris Agreement will require dramatic reductions in GHG emissions for the agricultural sector to meet its objectives.

In the US, efforts to regulate greenhouse gas emissions generally have been through the implementation of Clean Air Act regulatory programs or other programs targeted at the energy and transportation sectors and have not focused on agricultural activities. ${ }^{48}$ To achieve significant reductions in GHGs from agriculture, strategies will need to be implemented that are tailored to address the types of activities that take place in the agricultural world. Such strategies will not fit neatly into programs designed to reduce emissions from the energy, transportation and industrial sectors. Agriculture-targeted mitigation strategies include improved energy efficiency on the farm, reduced use of fossil fuel-derived synthetic fertilizers and pesticides, reduced use of fossil fuels to run heavy farm equipment, transportation and processing equipment, and the creation of local or regional food systems that decrease the distances that agricultural products are transported to their end users.

The FAO has argued in favor of global adoption of agricultural mitigation 'best practices'. These best practices would contribute to the FAO's articulated mitigation goals: reducing $\mathrm{CO}_{2}$ emissions, reducing methane and nitrous oxide emissions and sequestering carbon. ${ }^{49}$ Agricultural mitigation best practices geared toward reducing $\mathrm{CO}_{2}$ emissions include reducing land conversion and deforestation rates, increasing energy efficiency in the commercial agriculture and agro-industrial sectors and improving control of wildfire and burning associated with agricultural fields. ${ }^{50}$ Best practices aimed at reducing methane and nitrous oxide emissions include improving livestock nutrition, increasing management efficiency of wastes from livestock, increasing efficiency of nitrogen fertilizer applications in cultivation and reusing treated wastewater for irrigation. ${ }^{51}$

48 Prevention of Significant Deterioration and Title V Greenhouse Gas Tailoring Rule, 75 Fed. Reg. 31514, 31520 (3 June 2010); Memorandum of 25 June 2013-Power Sector Carbon Pollution Standards 78 Fed. Reg. 126 (1 July 2013), accessed 10 October 2016 at http://www.gpo.gov/fdsys/pkg/FR2013-07-01/html/2013-15941.htm; Carbon Pollution Emission Guidelines for Existing Stationary Sources: Electric Utility Generating Units 2015, 80 FR 64662. (Following the issuance of the regulation, the rule was challenged by a group of petitioners including electricity companies. On 9 February 2016, the Supreme Court stayed implementation of the Clean Power Plan pending judicial review.)

$\begin{array}{ll}{ }_{49}^{49} & \text { Ibid. } \\ { }_{50} & \text { Ibid. } \\ { }_{51} & \text { Ibid. }\end{array}$




\section{Research handbook on climate change and agricultural law}

To achieve the goal of sequestering carbon, FAO suggests best practices such as improved pasture and grazing management in grasslands, improved management of organic matter in soils, minimized mechanical soil disturbance, increased use of marginal lands for planted forests or cellulosic biomass, planting trees for carbon sequestration purposes and the 'introduction of integrated agroforestry systems that combine crops, grazing lands and trees in ecologically sustainable ways'. ${ }^{52}$ According to the FAO, these practices could have the collateral benefit of strengthening global food security by increasing market stability, providing agricultural employment opportunities, and boosting the sustainability of vulnerable agricultural systems. ${ }^{53}$

Animal production holds promise for significant mitigation, as Michelle Nowlin and Emily Spiegel explain in Chapter 9, because intensive animal agriculture is a significant emitter of the most potent GHGs. This chapter presents several mitigation measures and regulatory tools that are emerging to reduce GHG contributions from large-scale animal protection.

Another mitigation strategy that has received widespread attention in recent years is a reduction of food waste and loss. Currently approximately one-third of food produced is lost or wasted. From an economic standpoint, this represents a loss of approximately 2.6 trillion dollars. ${ }^{54}$ Moreover at a global scale food loss and waste contributes approximately 8 percent of all annual GHG emissions, accounting for approximately 3.3 gigatons of $\mathrm{CO}_{2}$ equivalents. ${ }^{55}$ In the United States in particular, 31 percent (133 billion pounds of the 430 billion pounds) of the available food supply in the United States in 2010 went uneaten. ${ }^{56}$

Reducing food waste can serve as an important mitigation strategy because it will result in a reduction in GHG emissions from producing, processing, transporting and disposing of the wasted food.

${ }_{52}$ Ibid.
Ibid.
54. 'If We Had to Pay the Bill to Nature, What Would Food Waste Cost Us?' (FAO, 17 September 2014), accessed 10 October 2016 at http://www.fao.org/ zhc/detail-events/en/c/243143/.

55 FAO, 'Food Wastage Footprint: Impacts on Natural Resources' (2013) 17, accessed 10 October 2016 at http://www.fao.org/docrep/018/i3347e/i3347e.pdf.

56 Jean C Buzby, et al., United States Department of Agriculture, 'The Estimated Amount, Value, and Calories of Postharvest Food Losses at the Retail and Consumer Levels in the United States' (2014) 11, accessed 10 October 2016 at http://www.ers.usda.gov/media/1282296/eib121.pdf. 


\subsection{Adaptation Strategies}

According to the US Global Change Research Program, adaptation 'refers to changes made to better respond to present or future climatic and other environmental conditions, thereby reducing harm or taking advantage of opportunity'. ${ }^{57}$ Adaptation will be crucial even if significant mitigation strategies are implemented. Based on the assumption that at least some climate change impacts will occur even if atmospheric GHG concentrations are stabilized through mitigation, adaptation strategies focus on strengthening natural and human systems' capacity to withstand changing conditions. ${ }^{58}$

Adaptation strategies include both technological and institutional policy changes. Examples of technological adaptations include improved crop varieties that are resistant to disease, drought or other climate change-induced conditions $;{ }^{59}$ more efficient water conservation measures; ${ }^{60}$ improved irrigation systems; ${ }^{61}$ and development of better weather forecasting systems. ${ }^{62}$ Institutional and policy changes discussed typically involve increased governmental support, including in the form of subsidies and incentives for adaptive farming practices. ${ }^{63}$

The FAO has set forth three overarching goals of adaptation for agriculture:

(1) protecting food production systems against increasing variability and extremes in weather patterns;

(2) minimizing disruptive impacts to food supplies from temperature increases and altered precipitation patterns; and

57 USGCRP, Impact Report, above note 45.

58 Lindsay F Wiley, 'Mitigation/Adaptation and Health: Health Policymaking in the Global Response to Climate Change and Implications for Other Upstream Determinants' (2010) 38 J.L. Med. \& Ethics 629, 631.

59 NV Fedoroff et al., 'Radically Rethinking Agriculture for the 21st Century' (2010) 327 Science 833, 833.

60 Anita Wreford et al., Organisation for Economic Co-operation and Development, 'Climate Change and Agriculture: Impacts, Adaptation and Mitigation' (2010) 20,67 .

${ }_{61}$ World Bank, World Development Report 2008, 'Adaptation and Mitigation of Climate Change in Agriculture' 2 ('World Development Report), accessed 10 October 2016 at http://siteresources.worldbank.org/INTWDRS/Resources/4773651327599046334/Brief_AdptMitClimateChng_web.pdf.

62 World Development Report, above note 61.

63 Shikui Dong, et al., 'Vulnerability of Worldwide Pastoralism to Global Changes and Interdisciplinary Strategies for Sustainable Pastoralism' (2011) 16 Ecology and Society 10, 24. 
(3) protecting natural systems through enhanced provision of environmental services. ${ }^{64}$

Agricultural adaptation practices that would address the first goal include research, development and dissemination of new adaptive crop varieties either through traditional breeding or genetic modification. ${ }^{65}$ Practices to meet the second goal include more efficient water management, improved livestock management and increased energy efficiency within the agroindustrial sector. ${ }^{66}$ As to the third goal ecosystem provisioning services could be enhanced through practices such as planting forests or other cellulosic biomass on degraded or marginalized land as carbon sinks, implementing watershed protection measures and planting on-farm refugia to promote biodiversity. ${ }^{67}$

Planning, including land use planning, will play an important role in adaption. In Chapter 8 Keith Hirokawa addresses the role of land use planning in adaptation. He describes how impacts of climate change are first experienced at a local level and emphasizes the significant role that local governments have played and continue to play in preparing for climate change. Hirokawa examines several local land use regulatory schemes that address predicted vulnerabilities related to food production and food security.

On a related topic, in Chapter 14 Amanda Kennedy and Amy Cosby address issues related to agricultural land use conflict in the context of climate change. Using a case study from Australia the authors explore the conflicts between agriculture and fossil fuel exploration created by increasing global energy demand. This chapter describes regulatory reforms that have been employed, albeit with modest success, to address these conflicts. The authors assert that existing regulatory instruments that disempower rural stakeholders by giving priority to the economic benefits of extractive industries exacerbate, rather than resolve, these conflicts. The authors conclude by presenting an alternative approach, which views land use conflict through the lens of environmental justice to ensure agricultural interests and the opportunity for meaningful participation in land use decisionmaking. To ensure food security in the face of climate change, it is critical that adaptation planning efforts focus on reforming agricultural systems on a local level. The United Nations Secretary General Special Report

${ }_{64}$ FAO Food Security, above note 40 at 31.
65 Ibid.
${ }_{66}$ Ibid.
67 Ibid.


concludes that our agricultural system must be reshaped to be regenerative and smallholder centered. ${ }^{68}$ In Chapter 13 Robert Kibugi addresses the need for and challenges of reforming smallholder farms in poor rural areas in Africa.

\section{CLIMATE RESILIENT AGRICULTURE AS BOTH A MITIGATION AND ADAPTATION STRATEGY}

In Chapter 3 Lance Gunderson explores the ways in which agriculture can adapt to climate change using a 'systems' framework, which takes into account the relationships among many elements or components to explain patterns and properties of complex phenomena. Gunderson describes agro-ecosystems as complex adaptive and dynamic systems and explores the need for managing such systems for resilience and transformation. This chapter also discusses the factors that contribute to declining resilience including a decrease in functional diversity and erosion of various forms of capital and limitations on systems capacity for renewal and regeneration in the context of climate change. Building on the 'systems' concept, in Chapter 4 Paul Martin posits that the human challenge of climate change will force adaptation within the law, which will extend beyond the usual regulatory fixes. In this chapter Martin proposes a novel approach to address the complexity of climate change employing 'systems thinking' as a way to address climate governance.

Gunderson and Martin's focus on systems approaches highlight the complex interactions at play in agricultural production and food value chain systems and the need to capitalize on those interactions to build resiliency into those systems. Agricultural systems, as types of ecosystems, can benefit from increased ecological resilience. The concept of ecological resilience captures the strength of redundancies in ecosystems from reinforcing processes and substituting functions provided by the presence of a diversity of species. The redundancies inherent in a diverse ecosystem enable the system to absorb perturbations and persist despite the disruption. ${ }^{69}$ In the agricultural context a resilient agro-ecosystem has the ability to continue to function and produce despite disruptions such as increased pest populations, disease or changed rainfall patterns.

68 UN News Centre 'Small Farmers Can Be Major Actors in Reducing Agriculture's Carbon Footprint' (UN News Centre, 8 July 2015), accessed 10 October 2016 at http://www.un.org/apps/news/story.asp?NewsID=51358\#. V1eM2mY4hok.

69 Ibid at 6. 
Agricultural ecosystems with high levels of resilience are more likely to be able to withstand a greater range of climate change-induced perturbations than are those lacking resilience.

For an agricultural ecosystem to be resilient several factors must be present. One of the most significant factors is an increase in species richness. Individual species each perform specific limited ecosystem functions. Greater species richness translates into greater functional diversity in the ecosystem. ${ }^{70}$ The presence of multiple species that can compensate for the loss of functions provided by other species imbues the systems with the ability to dampen the effects of perturbations, such as those resulting from climate change. ${ }^{71}$ Consequently the creation of a resilient agriculture depends on sufficient redundancy built into the systems so that unexpected disturbances, whether anthropogenic or natural, can be absorbed without causing the system to collapse. Introducing a diverse array of species into the agricultural system is the best way to accomplish this goal.

One of the greatest challenges to promoting and enhancing biodiversity in agricultural systems is invasive species. Invasive species can reduce biodiversity by outcompeting numerous native species, thereby dramatically reducing the number and abundance of diverse species. In addition, invasive species that become crop pests may create the need for substantial chemical pesticide use, which can reduce biodiversity by killing the natural diversity of pest predators and parasites that exist in and near croplands. In Chapter 6 Elodie Le Gal provides an in-depth description of the complexity and uncertainty regarding the interactions between climate change and invasive species. This chapter explores the limited efficacy of invasive species law in climate adaptation to protect agriculture from increased numbers of invasive species.

In Chapter 10 Christian Häberli tackles the issue of resiliency from a different standpoint. Rather than look at the resiliency of agricultural production systems, Häberli addresses the resiliency of the food value chain under the present international regulatory framework and concludes that climate change mitigation and adaptation efforts must take into account the circumstances of weak states, small farmers and poor consumers with regard to trade liberalization and foreign investment. Häberli proposes a number of changes that are needed to build resiliency into the food value

70 Garry Peterson, Contagious Disturbance and Ecological Resilience ( $\mathrm{PhD}$ dissertation, University of Florida 1999) 209.

71 Lance H Gunderson, CS Holling, Lowell Pritchard, Jr and Garry Peterson, 'Resilience of Large-Scale Resource Systems' 9, in Lance H Gunderson and Lowell Pritchard, Jr (eds), Resilience and the Behavior of Large-Scale Systems (Island Press 2002). 
chain, including multilateral climate-smart best farming and processing practices which must be protected against legal challenges in the WTO. This chapter also highlights the fact that while poor consumers are particularly vulnerable to food prices increases, poor food producers rarely benefit from them. Climate action can yield the highest returns for agriculture as the primary source of economic activity for poor populations.

Current industrialized agricultural practices tend to reduce diversity and therefore are not resilient. In large-scale industrialized agriculture monoculture planting can cover hundreds, if not thousands, of acres. More resilient farming systems introduce and promote diversity both in number of crop types and types of crop varieties. Diverse crops and varieties are planted together in intercropping or rotated and natural refugia are provided on the farm to provide the biological diversity necessary to reduce vulnerability to change. Planting a variety of crop types can provide a safety net in case one crop is compromised by an outbreak of pests or disease. Moreover resilient agro-ecosystems maintain and protect natural populations of beneficial species such as predators and parasites of pest species, pollinators, soil microbes and a diverse array of other organisms. ${ }^{72}$ This is accomplished by reducing pesticide inputs that kill beneficial parasites and predators and by providing on-farm conditions that allow a diverse array of species to thrive.

The importance of building resilience into agricultural systems is highlighted by the FAO's 'climate smart' sourcebook. ${ }^{73}$ According to the FAO, climate smart agriculture integrates 'the three dimensions of sustainable development (economic, social and environmental) by jointly addressing food security and climate challenges' ${ }^{74}$ It is composed of three inter-related main pillars:

(1) Sustainably increasing agricultural productivity and incomes.

(2) Adapting and building resilience to climate change.

(3) Reducing and/or removing greenhouse gases emissions, where possible.

Goal number (3) can be achieved via the types of mitigation measures discussed in this volume. The adaptation strategies proposed in this volume with help to achieve goal number (1). To meet goal number (2) it will

72 Robin Kundis Craig, 'Stationarity Dead'- Long Live Transformation: Five Principles for Climate Change Adaptation Law' 34 Harv. Envtl. L. Rev. 9 (2010) (describing some activities that promote resilience in agricultural systems).

73 FAO 2013, 'Climate-Smart Agriculture Source Book' note 39 above.

74 Ibid. 
be necessary to integrate mitigation and adaption strategies to develop resilient agricultural systems.

\section{CONCLUSION}

This volume presents a diverse set of ideas related to climate change and agriculture representing a wide variety of perspectives in terms of field of study and geographic perspective.

Although a wide range of ideas and perspectives are presented, several common themes emerge. Climate change and agriculture are part of a complex web of science, law and policy, which extends from the global scale to the smallholder. Agriculture is a significant contributor to climate change and thus should be considered part of the solution, as well as part of the problem. Consequently changes to agricultural systems that reduce GHG emissions, sequester carbon or put land to use in ways that reduce overall atmospheric carbon can be important tools for climate change mitigation. Conversely agriculture in general, and food security in particular, will suffer serious adverse impacts from climate change even with mitigation measures in place. Accordingly agricultural adaptation strategies targeted at agricultural production will be critical to ensuring food security in the future. Because of the pervasive complexity and uncertainty regarding climate change impacts on agriculture, it will be important to ensure that any adaption efforts employ systems approaches aimed at building resiliency in agricultural production as well as in the entire agricultural value chain. In many cases resilient agricultural systems are comprised of both mitigation and adaptive elements. Thus building more resilient systems will have benefits in reducing the adverse effects of climate change as well as adapting to the inevitable effects that will occur. Although climate change will result in adverse impacts throughout the globe, disproportionate impacts will be felt by the poorest and most vulnerable populations. Regions of the developing world face the greatest threats to food security. Mitigation and adaptation strategies, including regulatory and financial policies must include measures to ensure greater food security for poor and vulnerable populations. This volume provides a number of proposals for climate change mitigation and adaptation aimed at providing food security for a growing population in an era of dramatic changes to the global environment. 